\title{
The e-Flow Audit: An Evaluation of Knowledge Flow Within and Outside a High-tech Firm
}

\author{
by \\ Dr. Nick Bontis \\ Assistant Professor, Strategic Management \\ DeGroote School of Business, McMaster University \\ 1280 Main Street West, MGD \#207 \\ Hamilton, Ontario Canada L8S 4M4 \\ Tel: (905) 525-9140 x23918 Fax: (905) 521-8995 \\ nbontis@mcmaster.ca \\ www.Bontis.com \\ and \\ Michael Fearon \\ Research Associate \\ DeGroote School of Business, McMaster University \\ 1280 Main Street West, MGD \#207 \\ Hamilton, Ontario Canada L8S 4M4 \\ and \\ Marissa Hishon \\ Research Associate \\ DeGroote School of Business, McMaster University \\ 1280 Main Street West, MGD \#207 \\ Hamilton, Ontario Canada L8S 4M4
}

\section{Acknowledgement}

The authors would like to acknowledge the advanced technical computer support of Sam Sgambato and Maria Sgambato in the development of the e-Flow Audit. Please refer to www.bontis.com/research.htm for related papers on this topic.

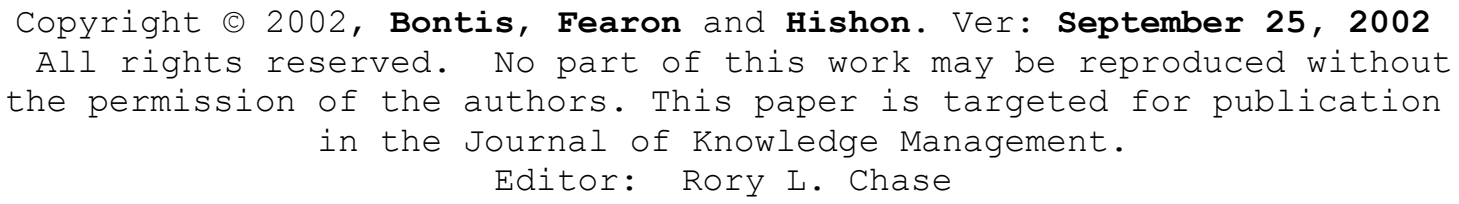




\title{
The e-Flow Audit: An Evaluation of Knowledge Flow Within and Outside a High-tech Firm
}

\begin{abstract}
Use of computer mediated communication, specifically electronic mail (email), has grown exponentially in recent years reaching as high as $75 \%$ penetration per household in some countries. The penetration rate is even higher for corporate environments (Wareham, 1999). E-mail is the communication medium of choice for most businesses and can therefore be construed as a proxy for codified knowledge flow in organizations (Bontis, 1999a; 1999b). This paper advances the knowledge management body of literature by empirically examining several phenomena. Specifically, a comparison is made between inter-and intra-departmental knowledge flows in organizations. Furthermore, knowledge flows within functional departments as well as knowledge flows to and from the external environment are examined. Data was collected from 15,500 e-mails logged over five random days in a high-tech organization of 480 employees. This data was then mapped onto the organizational chart and compared with the perceptual responses of a survey administration. Quantitative results were then triangulated with qualitative data gathered during focus groups. The research results yielded two important findings: 1) individuals showed an interesting bias towards overestimating their perceived knowledge flow throughout the organization, and 2) the eFlow Audit is an insightful managerial tool which provides a snapshot for knowledge management evaluation.
\end{abstract}

Abstract Word Count: 198 words

Text Word Count: 4,715 words

Key words: e-mail, knowledge flows, audit, intellectual capital 
When customers ask what's the first thing they can do to get more value out of their information systems and foster collaboration in their companies, I always answer e-mail.

Bill Gates (1999), Chairman of Microsoft

\section{Introduction}

Use of computer mediated communication, specifically electronic mail (e-mail), has grown exponentially in recent years. Wareham (1999) reports that e-mail remains the number one critical application on the Internet. An indication of the ubiquity of the application can be found in the level of Internet penetration of Canadian households; it has climbed from $31 \%$ in 1997 to $50 \%$ in 2000 to $75 \%$ in 2002 (AC Nielsen, 2002). For further evidence, one need only look to Hotmail, the free web-based e-mail service, to gain a true appreciation for this. By automatically appending a message which promotes the service to each outgoing message - a concept which later became known as "viral marketing" - Hotmail grew to 12 million subscribers in the first 18 months and signs up more than 150 thousand subscribers every day (Jurvetson and Draper, 1997).

There exists evidence that the e-mail phenomenon has manifested itself in an organizational context as well. The Washington, D.C.-based newsletter Electronic Mail and Messaging Systems (www.tr.com/newsletters/emms) reports that there are over 1 billion active e-mail users worldwide as of August, 2002. As e-mail continues to emerge as the communication medium of choice in organizations, an analysis of the dynamics unique to its use, and the organizational implications are of particular concern. The aforementioned viral marketing, for instance, has radically re-defined the traditional marketing views of "word-of-mouth" marketing. E-mail and the infrastructure on which e-mail is based, the Internet, enabled this evolution. Never before have we had a 
communication medium that allowed the broadcast of near-instantaneous, asynchronous communication with geographically remote locations at a negligible cost.

\section{Literature Review}

E-mail use in organizations began as an informal tool of communication. It was used in a similar manner to the Post-It note or memo (Lucas, 1998). The language used was colloquial; syntax was virtually absent. However, with the explosion of e-mail adoption in organizations worldwide, the applications have become increasingly more legitimate. E-mail is being used to direct company policy, to communicate with customers and to document important decisions. This evolution has not only changed the way organizations communicate, it has changed the structure of organizations themselves. Companies resemble the information systems that they rely on to do their work. As centralized, mainframe computer systems give way to distributed computer networks, the organization's future is a web structure and not a hierarchy. The question of what effects this has had on organizations is a topic of considerable debate. Has it disintegrated traditional vertical silos allowing more horizontal flows of communication? Has senior management empowered employees with the ability to make their voices heard at higher organizational levels? Has it also enabled management the reach to motivate and direct action across geographically distant locations (Lucas, 1998; CecezKecmanovic, 1999; Sproull and Kiesler, 1986)? Or, conversely, has it caused the ultimate depersonalization of communications, while reinforcing traditional power structures and hierarchies in the organization (Rice, 1990; Bikson et al., 1989; Child and Loveridge, 1990; Montovani, 1994)? 
Several theories exist that attempt to explain the adoption and use of media types such as e-mail in organizations: social presence (Rice, 1993; Short, Williams, Christie, 1976), critical mass (Markus, 1987), media richness (Daft and Lengel, 1986), social influence (Fulk, 1993; Schmitz and Fulk, 1991), structuration (Orlikowski, 1992; Orlikowski et al. 1995) and channel expansion theory (Carlson and Zmud, 1999). Of these four, not one perspective has emerged to fully explain the dynamics involved in media selection and use; rather, the most popular frameworks have evolved from a concentration of media richness theory to complimentary hybrids that incorporate increasing levels of complexity (Webster and Trevino, 1995). Social influence theory, for example, introduces social factors that influence individuals' perceptions of media and their use. An individual selects media based on their perceived media richness, social influence from co-workers and supervisors, and other factors such as time and distance, media accessibility and support.

Media richness theory explains the choice of media as being dependent upon the content of the message to be communicated. Media richness can be portrayed along a spectrum of available media types. At the richest extreme lies face-to-face communications; on the opposite end, representing the leanest media type, are written media. Rich media types, in contrast to lean types, provide for additional cues - like body language and voice intonation - that clarify potentially ambiguous communication (Daft and Lengel, 1986).

Channel expansion theory, a more recently developed extension of media richness theory, attempts to explain an individual's perception of media richness for a particular communication channel as being related to certain experiences such as experience with 
the channel, experience with the organizational context, and experience with communication co-participants. The theory asserts that as individuals develop these experiences, they develop a knowledge base, which allows them to leverage the channel more adeptly. For instance, as a user of e-mail becomes more comfortable with the technology, they learn how to communicate varying degrees of formality and richness. One way in which this can be accomplished is through the use of "emoticons" - a combination of characters that express emotional content (e.g. a colon and parenthesis configured as ":)" is called a smiley face and is used to denote the presence of humour or irony) (Carlson and Zmud, 1999).

In this paper, however, we endeavour to examine the value of e-mail as a mechanism of knowledge flow in organizations. Acceleration knowledge flow in organizations is a fundamental research issue in the field of knowledge management (Bontis, 2001a). Certainly the study of e-mail in this context cannot be considered exclusive of theories like media richness. An understanding of the factors involved that explain how employees choose a media type, their perceptions of different media types and their use of these media are all important to an understanding of e-mail as a proxy of codified knowledge flow in organizations (Bontis, 1999a; 1999b). We concede, however, to the pervasiveness of e-mail in organizations. Consequently, rather than focussing on why or when e-mail is chosen as a communication tool, we focus on its enormous potential value for perpetuating organizational knowledge. While the role of email in new knowledge creation is inherently constrained to some degree by its inability to carry fully rich message cues, as in face-to-face communications, it has evolved from a much a more limited capacity at its inception to a position that sees us using it to 
communicate increasingly more formal and more ambiguous messages. As the use of email continues to encroach upon more traditional means of communicating, we will likely continue to see its role expand; the experience effects described by Carlson and Zmud (1999) as well as the expanding technological abilities of e-mail - like the ability to carry multimedia content-will ensure this.

An alternative theoretical lens for our discussion of knowledge flow in organizations can be found in the work of Nonaka and Takeuchi (1995). Nonaka and Takeuchi (1995) examine how Japanese companies, in contrast to Western companies, have been successful in mobilizing knowledge assets both within and outside the organization. They describe organizational knowledge creation as a continuing interaction and exchange, called conversion, between tacit and explicit knowledge. Nonaka and Takeuchi (1995) go on to present a model of knowledge conversion comprised of four modes: socialization, externalization, combination, and internalization. It is clear that e-mail is limited in its capacity to transfer tacit knowledge from person to person. However, as a vehicle of explicit knowledge flow the ability of e-mail - through its intrinsic technical characteristics - to amplify individual level knowledge to organizational and inter-organizational levels is unparalleled. In fact, e-mail has the capability of playing a significant role in three of the four modes of knowledge conversion: externalization, combination and internalization. E-mail facilitates externalization (tacit to explicit) through dissemination of individual knowledge to others in the organization. It also assists in this effort through redundancy, one of the key characteristics that is necessary for conversion from tacit to explicit knowledge. Redundancy is important because it encourages frequent dialogue and communication. 
This helps create a "common cognitive ground" among employees and thus facilitates the transfer of tacit knowledge. Since members of the organization share overlapping information, they can sense what others are struggling to articulate. Redundancy, which takes place primarily in information sharing, also spreads new explicit knowledge through the organization so that it can be internalized by employees (Nonaka and Takeuchi, 1995).

Preiss (1999) articulates a seemingly contrary view of knowledge flow in this regard. He likens the flow of knowledge to that of a production process. The concept of a "balanced production line" where the throughput capacity of each work process is exactly equal is not possible - a bottleneck is inevitably created. He argues that in a knowledge flow system it is a wasteful overload to have all the knowledge distributed to every process all the time, just as it is wasteful and damaging to the efficiency of each process to have material distributed more widely than is needed (Preiss, 1999). Preiss also states that the advent of computer communication has made the availability of explicit knowledge commonplace as a commodity accessible to all people and all processes that are connected to the Internet. Given that the distribution of this information is universal, competitive advantage is gained from the information about the information. The system has moved from "push" where competitive advantage relies on access to information, to "pull" where competitive advantage relies on the capability of the user of the information to ingest it. This is where the knowledge bottleneck lies (Preiss, 1999). The remedy is to employ filtering and monitoring of the information before it gets to the individual. In this age of information overload, a compromise position between an environment encouraging redundancy and one attempting to avoid 
knowledge bottlenecks, where sufficient, yet discretionary, knowledge sharing is performed via e-mail is probably the most effective approach.

Perhaps the most obvious position for e-mail in Nonaka and Takeuchi's (1995) knowledge conversion process is combination (explicit to explicit). Here it facilitates the distribution of explicit knowledge, by increasing the number of people capable of generating it. Internalization (explicit to tacit) represents the cogitation of the other conversion modes when it results in expanding individual understanding, or acquisition of tacit knowledge. An appreciation for the role that e-mail plays in this mode is clear from the description of the internalization process. For explicit knowledge to become tacit, it helps if the knowledge is verbalized or diagrammed into documents, manuals, or oral stories. Documentation helps individuals internalize what they experienced, thus enriching their tacit knowledge (Nonaka and Takeuchi, 1995).

Having established the value of e-mail as a legitimate authoring and dissemination tool for codified organizational knowledge, it is incumbent upon us to question how, or if, the organization is tracking, maintaining or - perhaps more important - leveraging e-mail as a knowledge resource of the organization. Lucas (1998) came to the conclusion that information flows, while more efficient due to e-mail, have become too voluminous to be managed effectively at an organizational level. This has shifted responsibility and discretion of the value of e-mail to the individual employee level. While this is encouraging news for all employees because it allows the organization to better leverage its intellectual capital (see Bontis, 1996, 1998, 2000; Bontis et al., 1999; Bontis et al., 2000a; Bontis et al., 2000b), it is also cause for some concern. The reality is that few organizations have a proactive policy regarding the management of electronic 
messages as records of the organization, which leaves end users without any guideline for determining the value and disposition of their e-mail (the only exception here is public service and government organizations which are legislated to store all electronic correspondence). As surprising as it may seem, many organizations have only ad hoc programs of printing important e-mail messages to paper rather than attempting to manage them digitally (Enneking, 1998).

An essential component of what is required to become a knowledge-enabled organization is to ensure that all employees are able to locate, access and utilize the knowledge and skills they need to meet their individual and company goals (Tobin, 1998). The body of data and information laying dormant in e-mail systems, when utilized properly - through indexing, profiling and categorizing - has tremendous potential to create new organizational knowledge, and therefore, to equip employees with the resources they need to accomplish these objectives. Technology is emerging that will transparently review each piece of e-mail indexing it and creating profile databases that are accessible to everyone in the organization. The e-mail server, when transformed into a knowledge asset of this form, becomes not only a tremendous source of explicit knowledge, but also a facilitator of new tacit knowledge creation by bridging current skills and expertise in the organization to those who need it.

The advent of the knowledge era has made the use of knowledge repositories critical for organizational learning (Bontis, Crossan and Hulland, 2002) and the strategic management of knowledge assets (Bontis, 2002a; 2002b; Choo and Bontis, 2002). However, the proliferation of technology - like e-mail - has blurred organizational boundaries effectively facilitating the ease with which an individual can move from one 
company to another and plug into different projects along the way. This has created a challenge for firms to find new and creative ways to capture their intellectual capital assets (Bontis et al., 1999c). Brown (1998) warns that managing intellectual capital comes down to fundamental and very transparent common sense such as not letting your smartest workers, or the best ideas get away. E-mail provides a lasting fingerprint of intellectual capital in a corporate environment marked by increasing employee transience.

\section{Research Methodology}

The objective of this research is to map the flow of codified knowledge through a corporation, using e-mail traffic as a measurement proxy. We venture to gain a better understanding of knowledge flow through intra-departmental and inter-departmental email traffic, as well as e-mail travelling in and out of the organization itself. We followed five main steps in our e-Flow Audit research methodology:

- A study of the digital flow of e-mail both inside and outside of the firm;

- A mapping of this flow of e-mail onto a consolidated organizational chart;

- An examination of how e-mail is used by the firm's employees;

- An examination of the e-mail which is sent to and from the firm's employees; and

- An examination of the factors which affect the use of e-mail.

The research was conducted at a high-tech, knowledge-intensive firm, headquartered in Burlington, Ontario, Canada. At this firm, 480 employees generate an annual revenue of nearly $\$ 84$ million. To construct a model of how e-mail flows through the company, a log file was extracted from the firm's SMTP server to determine the path of each discrete e-mail that was sent and received. Approximately 15,500 messages were collected over a random five-day period. The content of these e-mails was private and confidential and thus not examined for the purposes of this study. Due to the format of this $\log$ file, only the "from" and "to" header information was utilized; the "cc" and "bcc" 
fields were deemed to be less valuable as a measure of direct knowledge flow and were thus excluded from consideration. Feedback from the organization was inconsistent as to whether these carbon-copies and blind-copies of e-mail constituted a relevant flow of knowledge within the company - in fact, company culture often frowned upon the overuse and abuse of the functionality. In the words of the CIS Manager for instance: “As soon as you get the title 'manager', you get 'cc'd' on everything and your inbox soon becomes unbearable."

A database management system (DBMS) was then used to analyze the figures obtained from the file using an algorithm specifically designed for this study. The original organizational structure, comprised of 44 departments, was collapsed into four primary departments to ensure ease of analysis and a meaningful representation of our results. Given the manufacturing-intensive nature of the organization, manufacturing was divided into two departments: 1) Silicon Operations and 2) Test Operations. The remaining two organizational elements are 3) Marketing and 4) Sales \& Finance, which includes Purchasing, Administration and CIS (computer information systems). These four classifications, while perhaps not intuitive, were based on the reporting relationships of each department as verified by senior management. The results of the DBMS analysis were mapped onto the organizational chart, to derive a quantitatively-based, physical map of e-mail flow.

In addition, a web-based survey was administered to the employees of the firm. This survey consisted of 20 questions regarding their perception of e-mail usage at the company: the time spent using e-mail daily, the relevance of e-mail, a rating of the preference for e-mail over other conventional means of communication, and the 
employees' sense of where their e-mails are going and coming from. To introduce the survey to the employees, a cover letter was attached explaining the purpose of the study, in hopes that this would increase the response rate. The survey was administered through the CIS department of the firm, using an Internet host (www.zoomerang.com). Each employee at the firm (who has dedicated e-mail access) was sent a link to the site and asked to complete the survey questions. The CIS Manager sent two reminder e-mails to all employees following the initial survey launch and cover letter, requesting that those who had not yet filled out the survey do so. Out of a possible 452 eligible respondents, a total of 128 responses were recorded during the three-week survey window, yielding a response rate of $28.3 \%$ which is favourable given the intense nature of the business and the employees' extremely busy schedules.

Two subsequent interviews with the CIS Manager were conducted to assess his opinion on the survey findings as well as the actual results determined by the DBMS analysis of the log file. Finally, a focus group was held subsequent to the survey study involving six random employees of the company, from different departments and levels in the organizational structure. The participants were asked their opinions on both the survey findings and the actual results from the SMTP log file summary. They were also invited to provide any additional comments regarding their use of e-mail and the culture of e-mail usage at the firm.

\section{Discussion of Results}

We wanted to determine the proportion of e-mail traveling out of the firm, into the firm, and within the firm. The DBMS analysis of the SMTP log file data yielded the following macro-level results: the outcome of the one-week sample was that 2,419 
messages were sent from the firm to outside sources, 5,639 messages were sent from outside sources to the firm, and 7,125 messages were sent inter-and intra-departmentally (see Figure 1). Proportionally, this means that there was about 2.3 times $(5,639 \div 2,419)$ the number of messages entering the company as were being sent out. Almost three times as many messages were sent to recipients in the company, between and within departments, as were sent to outside sources $(7,125 \div 2,419)$. During the focus group, the consensus among employees was that this was a typical representation of their e-mail volume.

--- place Figure 1 about here ---

We then looked at the e-mail traffic in more detail. The number of messages from the firm to outside sources was 2,419 . This was broken down into the number of messages sent by each department in a week. The finance department sent 496 messages, marketing and sales 639 , silicon operations 636 , and test operations 648 . These numbers are roughly equal and indicate, in terms of raw volume, that the quantity of e-mail messages leaving each department is approximately the same. However, by further breaking down the data into e-mails per employee, significant differences emerge (see Figure 2).

--- place Figure 2 about here ---

Marketing and sales showed an average of about 11 messages per employee per day to outside sources, while test operations yielded just over three. Although it is likely that certain departments and employees naturally communicate more with outside sources, the lack of outside communication may signal a deficiency in relational capital accumulation (Bontis, 2001b). The survey results show that on average, an employee 
believes that he/she sends out about 11 messages each day. Of these messages, 74\% were estimated to be to recipients within the company, with the remainder transmitted to outside sources. This translates to about three messages a day, or 15 during the course of a work week. The actual results logged in the SMTP file show that between three and 11 messages were sent per employee, depending on department. This demonstrates a disparity between the perceived volume of outgoing e-mail versus the actual measured volume. Focus group feedback indicated that the discrepancy between outward flow versus inward flow could be attributed to the lean nature of the organizational structure; because the business is growing financially without a corresponding growth in staff size, it has become difficult to engage with fellow colleagues on a real-time basis. Firm employees have resorted to e-mail due to its asynchronous benefits.

The total number of e-mails $(5,639)$ flowing into the company was also dissected further. The departments received the following messages: finance (931), marketing and sales $(1,263)$, silicon operations $(1,162)$, and test operations $(2,154)$. Again looking at messages received per employee, a skew is seen toward certain departments. Marketing and sales received 23 e-mail messages per employee per day, while at the opposite extreme silicon operations received just over 8 e-mails per day (see Figure 3).

--- place Figure 3 about here ---

From the responses to the survey, employees thought that they received, on average, 18 e-mails per day. Of these, $29 \%$ were believed to originate from outside the company, meaning five messages per employee per day were perceived to be received from outside sources. The SMTP data as shown above indicates that between eight and 23 e-mail messages per employee per day were received from outside the firm. In this 
case, the employees underestimated their perceived e-mail interaction with individuals outside the company.

By analyzing the SMTP log file data, we were also able to compare the intradepartmental and inter-departmental knowledge flow in the company. We used the number of messages sent within the firm $(7,125)$ as the base, and looked at which department sent or received the e-mails. It is clear after visually displaying the data that the firm is biased toward intra-departmental knowledge flow versus inter-departmental flow. This can be seen in the diagonal stack of bars that represent e-mail flows per employee within his or her own department. For each department, the number of messages to other employees in the same department out-numbered the quantity of messages sent to each of the three other departments. However, results of the survey show that of the e-mail received from within the company, there is a perceived balance in volume between inter- and intra-departmental communication (41\% and 44\% respectively). Once again, we see discrepancy in perceived e-mail usage versus actual. The actual log file of e-mails proves that knowledge flows across departments are still relatively weak.

\section{--- place Figure 4 about here ---}

To further examine this phenomenon, we examined the vertical flows within the company. Survey results showed that an average of $53 \%$ of e-mails received from within the company are from peers, while an average of only $27 \%$ are from supervisors or senior management. However, the actual e-mail log files show an average of $56 \%$ of the emails are sent to peers, while an average of $27 \%$ are sent to supervisors or senior management. In this case, individuals were correct in their perceptions of relative 
knowledge flow to peers versus senior management at a ratio of 2 to 1 . However, this ratio also supports the notion that more knowledge is flowing horizontally than vertically.

Another way of representing the intra- and inter-departmental knowledge flows is depicted in our e-Flow Audit map. The circles represent each of the four consolidated departments. The sizes of the circles are scaled to the intra-departmental e-mail volume. The Marketing and Sales departments, for instance, has the highest degree of intradepartmental flows per employee, followed by Finance/CIS/Admin and so on. The vectors directed toward each individual department portray the relative amounts of interdepartmental e-mail traffic per employee. Therefore, the e-mail volume from Marketing and Sales to Silicon Operations, which is greater by a factor of three than the inverse traffic, is represented by a thicker vector. These relative relationships hold throughout the model. By representing the intra- and inter-departmental flows in this manner, one can quickly gauge the volume of codified knowledge flow in the organization.

--- place Figure 5 about here ---

An example of this sort of examination can be seen by isolating the flows to and from Marketing and Sales to both of the manufacturing components. Clearly, the flows from Marketing heavily outweigh the corresponding flows from either Silicon Operations or Test Operations back into Marketing.

What does this snapshot say about the interaction between these organizational elements? How about their willingness or perceived need to work with and communicate with one another? We've seen that Marketing and Sales communicates outside of the organization more so than other areas of the firm. Having depicted the intra- 
departmental flows in this alternative fashion, we can also see that Marketing has the highest degree of intra-departmental knowledge flow, as well as a superior level of interdepartmental flow. Does this mean that the Marketing and Sales function intrinsically requires more communication and, therefore, is poised to create and project greater knowledge flow? And, conversely, what does the model say about the meagre levels of intra- and inter-departmental flows of both manufacturing departments? Perhaps the nature of their mission is such that communication - or knowledge transfer - via e-mail, as opposed to other forms of interaction, is not key. The tremendous insight provided by the e-Flow Audit map at a glance allows one to see how the organization is performing with respect to knowledge management. Subsequent focus groups corroborated the results by identifying the Marketing and Sales group as more "close knit" whereas individuals in the manufacturing departments were described as "knowledge hoarders" and more socially distant.

\section{Conclusion}

We've seen how e-mail has evolved from a rudimentary form of communication, limited by its primitive usage, to a medium capable of imparting increasingly rich information. This evolution has enabled e-mail to mature into a legitimate organizational tool used for purposes such as documenting company policy and communicating with customers and suppliers. There is a disparity between the advanced applications of email and the lack of recognition on the part of the organization that e-mail is or should be a critical element of the organization's knowledge management strategy. This was observed both in the literature reviewed and our own audit of a knowledge-intensive firm. 
The body of research is conflicting in terms of what effects e-mail is believed to have on organizational communication: has e-mail disintegrated departmental silos or has it reinforced traditional hierarchies? Our examination does not dispel either assertion, but does tend to support the view that e-mail has democratized communication among firm employees. It has not, however, had the effect of breaking down the ingrained cultural barriers to vertical and horizontal freedom of knowledge flow. The obvious bias at this firm toward intra-departmental and intra-firm communication demonstrates what we describe as the "knowledge hibernation phenomenon". Nonaka and Takeuchi (1995) argue that new knowledge creation is a process not within individuals, but between them.

The firm studied in this case claims to have a knowledge management strategy; however, its e-mail system has not been identified as a component of that strategy. The knowledge management implication for this firm is that competitiveness might be hindered to the extent that it depends on the creation and exchange of knowledge within and outside the firm. A strategy that considers the dynamics of tacit versus explicit knowledge creation, and how the e-mail system of the firm can play a role in that regard, is what is required in order for the firm to fully leverage its e-mail system. Technological advancements such as the e-Flow Audit that that can aid senior management in fully evaluating their existing knowledge flows are critical for overall knowledge management success. 
Figure 1

Volume of e-mail messages

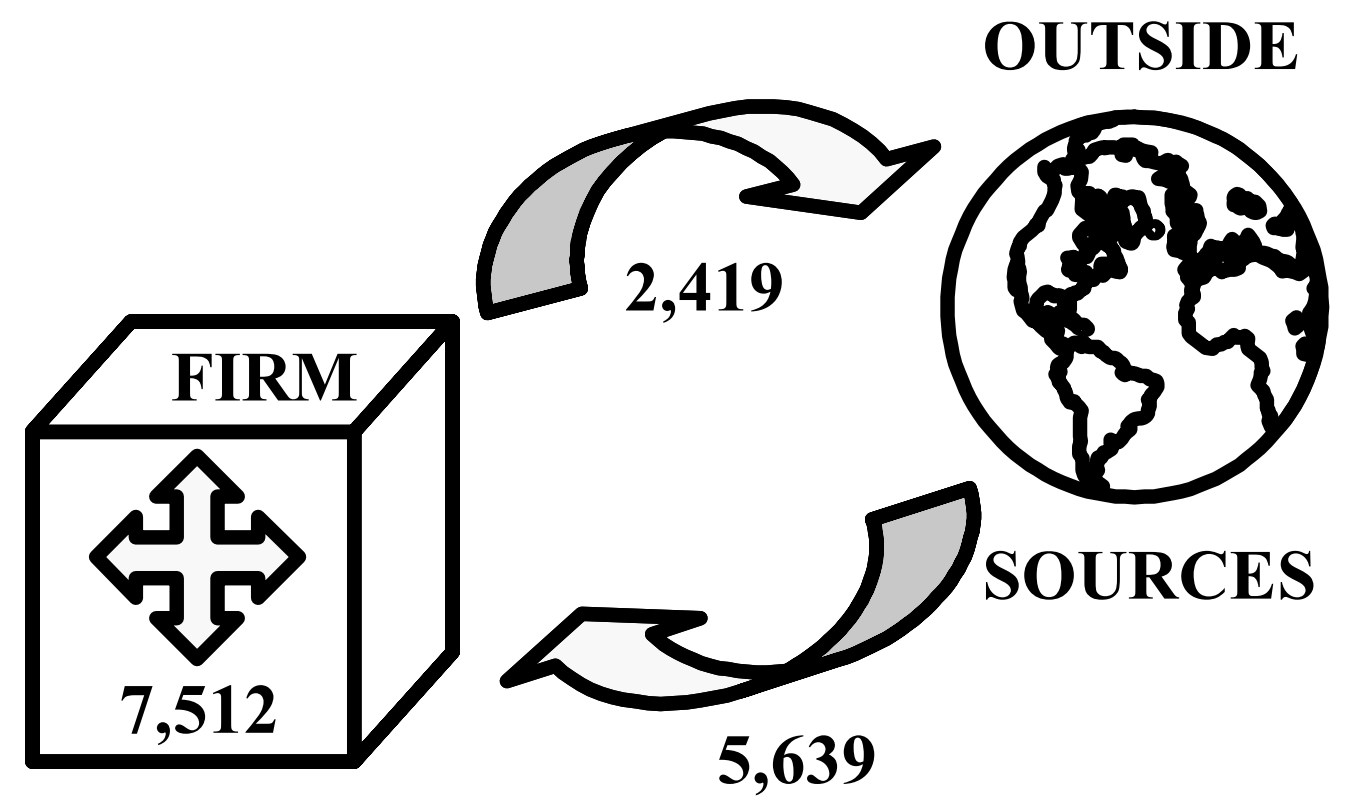


Figure 2

E-mails per employee from the firm to outside sources

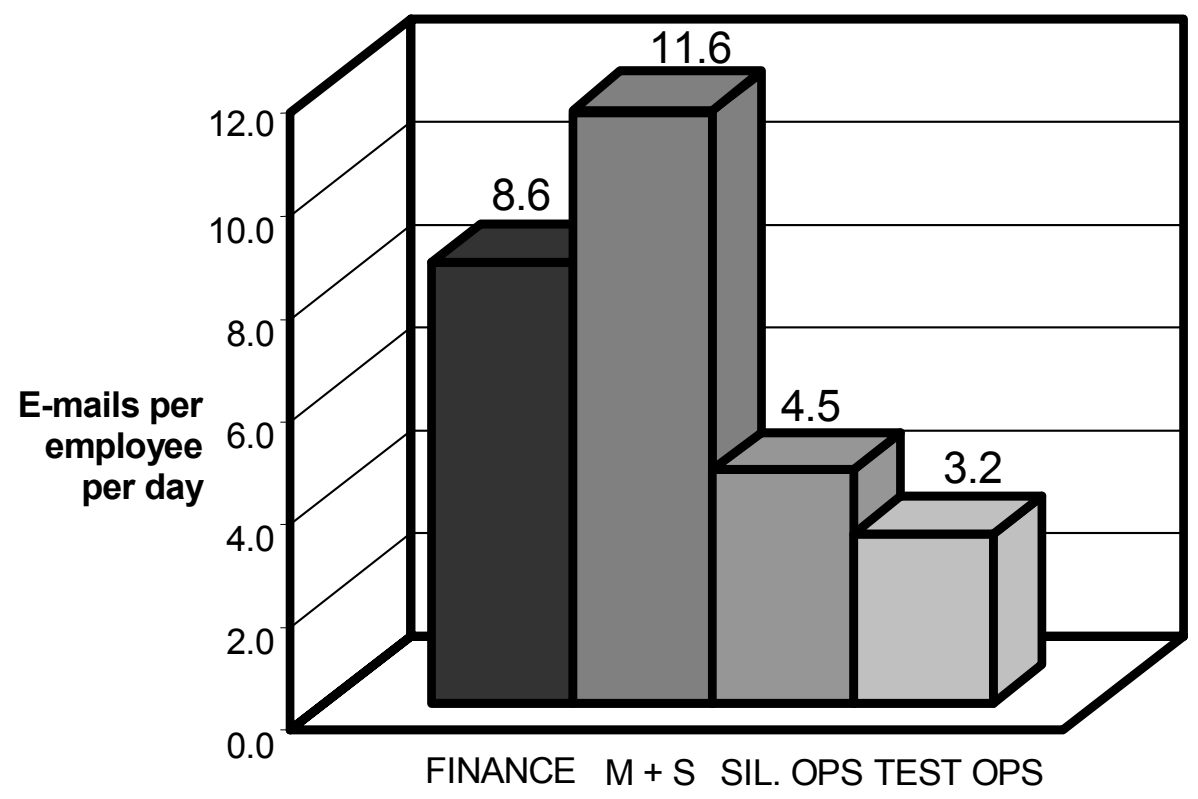

Figure 3

E-mails per employee from outside sources to the firm

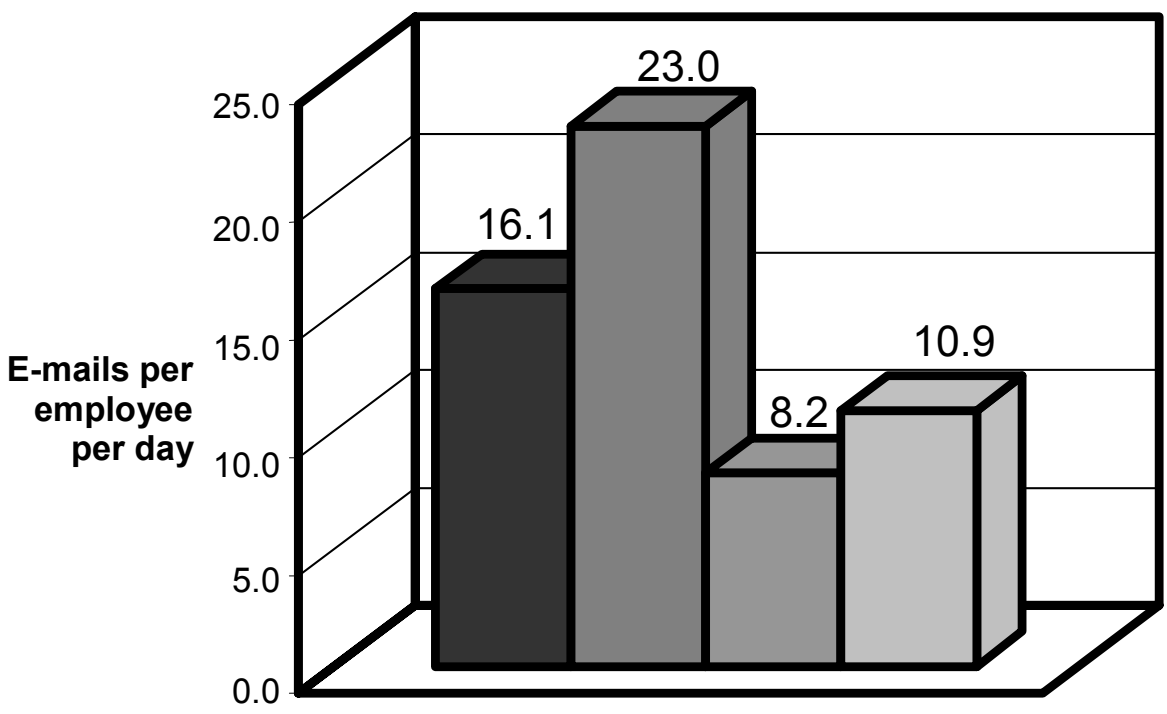

FINANCE $M+S$ SIL. OPS TEST OPS 
Figure 4

E-mails within the firm by department

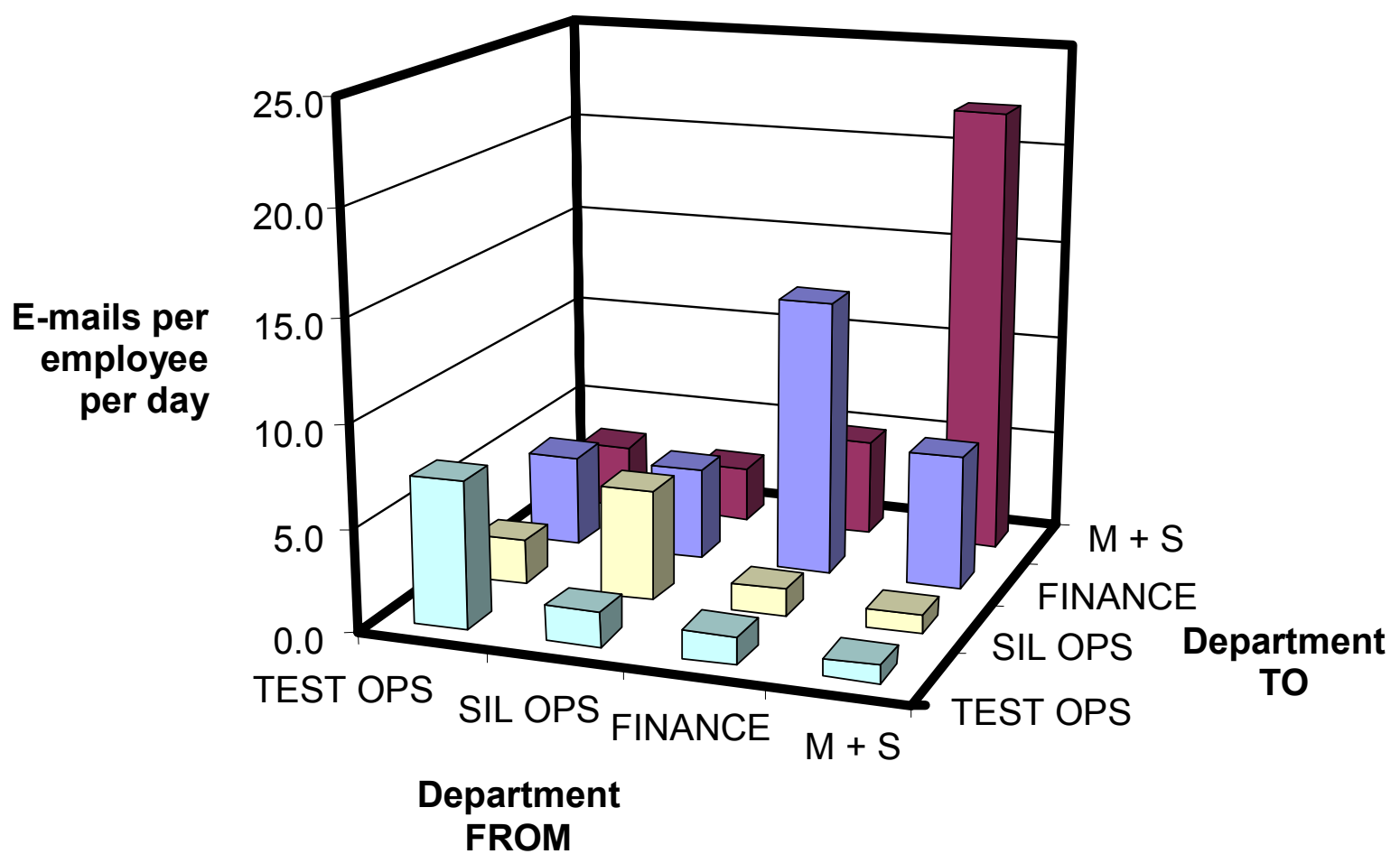


Figure 5

Mapping results of e-Flow Audit

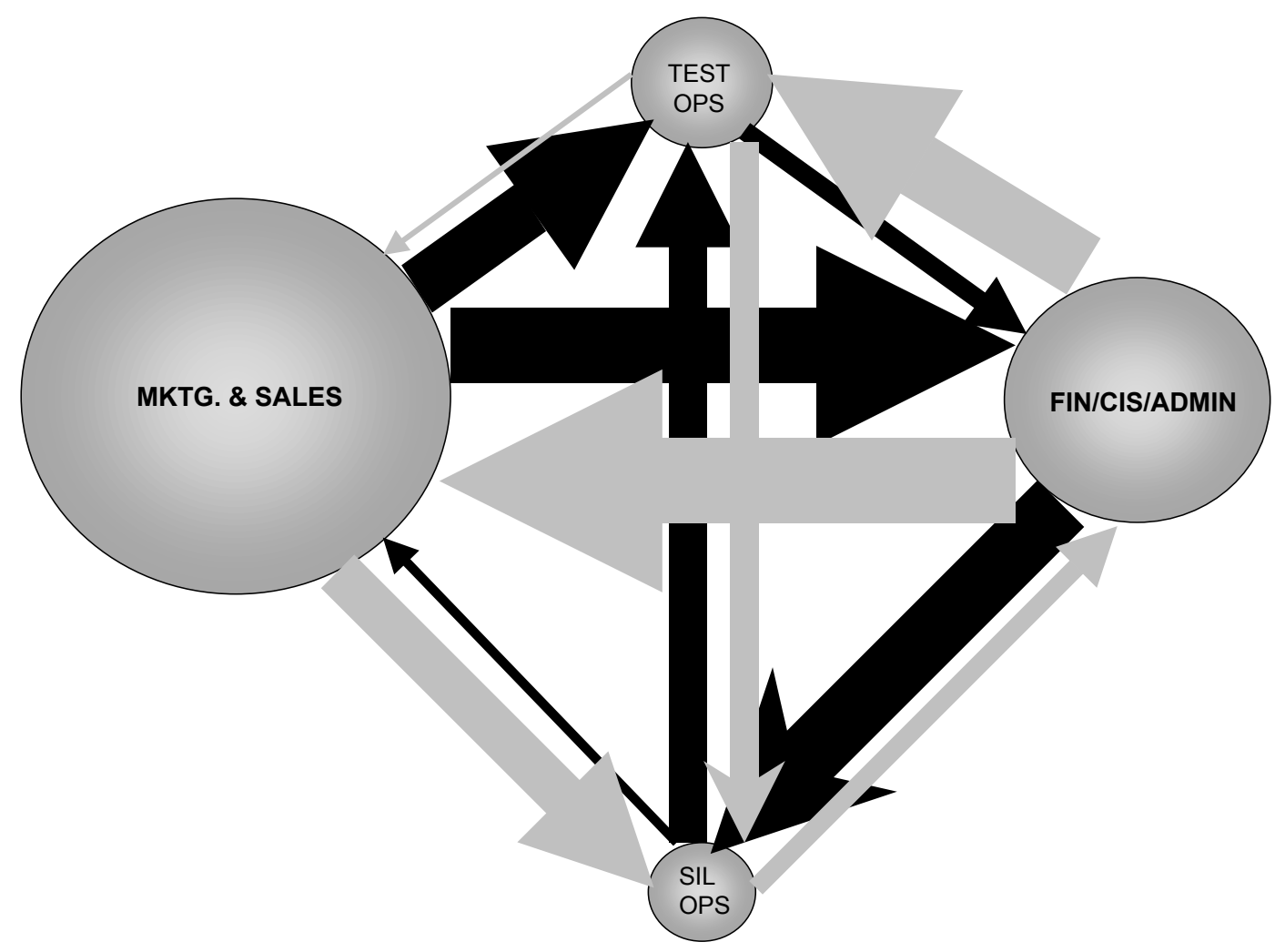




\section{References}

AC Nielsen. (2002), The Internet Fact Book, AC Nielson, Toronto, Canada.

Bikson, T., Eveland J. and Gurek, B. (1989), "Flexible Interactive Technologies for Multiperson Tasks: Current Problems and Future Prospects", in Olson, M.H. (Ed.) Technological Support for Workgroup Collaboration, Earlbaum, Hillsdale, NJ.

Bontis, N. (1996), “There's a Price on your Head: Managing Intellectual Capital Strategically", Business Quarterly, Summer, pp. 40-7.

Bontis, N. (1998), "Intellectual Capital: An exploratory study that develops measures and models", Management Decision, Vol. 36 No. 2, pp. 63-76.

Bontis, N. (1999a), "Managing an Organizational Learning System by Aligning Stocks and Flows of Knowledge: An empirical examination of intellectual capital, knowledge management and business performance", $P h D$ dissertation, London, Canada: Ivey School of Business, University of Western Ontario.

Bontis, N. (1999b), "Managing Organizational Knowledge by Diagnosing Intellectual Capital: Framing and advancing the state of the field", International Journal of Technology Management, Vol. 18 No. 5-8, pp. 433-62.

Bontis, N. (2001a), "CKO Wanted - Evangelical Skills Necessary: A review of the Chief Knowledge Officer position", Knowledge and Process Management, Vol. 8 No. 1, pp. 29-38.

Bontis, N. (2001b), "Assessing Knowledge Assets: A review of the models used to measure intellectual capital", International Journal of Management Reviews, Vol. 3 No. 1, pp. 41-60.

Bontis, N. (2002a), World Congress of Intellectual Capital Readings, Boston: Butterworth Heinemann KMCI Press.

Bontis, N. (2002b), “The rising star of the chief knowledge officer", Ivey Business Journal, Vol. 66 No. 4, pp. 20-5.

Bontis, N. and Girardi, J. (2000), "Teaching Knowledge Management and Intellectual Capital Lessons: An empirical examination of the TANGO simulation", International Journal of Technology Management, Vol. 20 No. 5-8, pp. 545-55.

Bontis, N., Chua, W. and Richardson, S. (2000), "Intellectual Capital and the Nature of Business in Malaysia", Journal of Intellectual Capital, Vol. 1 No. 1, pp. 85-100.

Bontis, N., Crossan, M. and Hulland, J. (2002), "Managing an Organizational Learning System by Aligning Stocks and Flows", Journal of Management Studies, Vol. 39 No. 4, pp. 437-69.

Bontis, N., Dragonetti, N., Jacobsen, K. and Roos, G. (1999), "The Knowledge Toolbox: A review of the tools available to measure and manage intangible resources", European Management Journal, Vol. 17 No. 4, pp. 391-402.

Brown, T. (1998), "Ringing up Intellectual Capital”, Management Review, Vol. 87, pp 47-51. 
Carlson, J. and Zmud, R. (1999), "Channel Expansion Theory and the Experiential Nature of Media Richness Perceptions”, Academy of Management Journal, Vol. 42, pp. 153-170.

Cecez-Kecmanovic, D., Moody, D., Busuttil, A. and Plesman, F. (1999), "Organisational Change Mediated by E-mail and Intranet: An Ethnographic Study", Information Technology \& People, Vol. 12 No. 1, pp. 9-26.

Child, J. and Loveridge, R. (1990), Information Technology in European Services Towards a Microelectronic Future, Blackwell, Oxford.

Choo, C.W. and Bontis, N. (2002), The Strategic Management of Intellectual Capital and Organizational Knowledge, Oxford University Press, New York.

Connolly, C. (1996), "Communication: Getting to the Heart of the Matter", Management Development Review, Vol. 9 No. 7, pp. 37-40.

Daft, R. \& Lengel, R. (1986), “Organizational Information Requirements, Media Richness and Structural Design”, Management Science, Vol. 32, pp. 554-7.

Dove, R. (1999), "Knowledge Management, Response Ability, and the Agile Enterprise", Journal of Knowledge Management, Vol. 3 No. 1, pp. 18-35.

Electronic Mail and Messaging Systems. (2002), www.tr.com/newsletters/emms, Accessed March 15, 2002.

Enneking, N. (1998), "Managing E-mail: Working Toward an Effective Solution”, Information Management Journal, Vol. 32 No. 3, pp. 24-43.

Eveland, J.D. and Bikson, T.K. (1987), "Evolving Electronic Communication Networks: An Empirical Assessment”, Office: Technology and People, Vol. 3 No. 2, pp. 103-28.

Feldman, M. (1987), "Electronic Mail and Weak Ties in Organizations", Office: Technology and People, Vol. 3 No. 2, pp. 83-101.

Fulk, J. (1993), "Social Construction of Communication Technology", Academy of Management Journal, Vol. 36, pp. 921-50.

Gates, B. (1999), Business@ @ the speed of thought: Succeeding in the digital economy, Warner, New York.

Harari, O. (1997), "Flood Your Organization With Knowledge”, Management Review, Vol. 86 No. 10, pp. 33-7.

Jurvetson, S. and Draper, T. (1997), "Viral Marketing", www.dfj.com/viralmarketing.html, Accessed March 28, 2000.

Lee, A.S. (1994), "Electronic Mail as a Medium for Rich Communication: An Empirical Investigation Using Hermeneutic Interpretation”, MIS Quarterly, Vol. 18 No. 2, pp. 143-60.

Lucas, W. (1998), "Effects of E-Mail on the Organization”, European Management Journal, Vol. 16 No. 1, pp. 18-29. 
Mantovani, G. (1994), "Is Computer-Mediated Communication Intrinsically Apt to Enhance Democracy in Organizations?", Human Relations, Vol. 47 No. 1, pp. 4562.

Markus, M. (1987), “Toward a 'Critical Mass' Theory of Interactive Media: Universal Access, Interdependence, and Diffusion”, Communication Research, Vol. 14, pp. 491-511.

Neef, D. (1999), "Making the Case for Knowledge Management: The Bigger Picture", Management Decision, Vol. 37 No. 1, pp. 72-8.

Nonaka, I. and Takeuchi, H. (1995), The Knowledge-Creating Company: How Japanese Companies Create the Dynamics of Innovation, Oxford University Press, New York.

Orlikowski, W. J. (1992), "The Duality of Technology: Rethinking the Concept of Technology in Organizations”, Organization Science, Vol. 3 No. 3, pp. 398-427.

Orlikowski, W. J., Yates, J., Orkamura, K., and Fujimoto, M. (1995), “Shaping Electronic Communication: The Metastructuring of Technology in the Context of Use", Organization Science, Vol. 6 No. 4, pp. 423-44.

Preiss, K. (1999), “Modelling of Knowledge Flows and Their Impact”, Journal of Knowledge Management, Vol. 3, pp. 36-46.

Rice, R. (1993), "Media Appropriateness: Using Social Presence Theory to Compare Traditional and New Organizational Media", Human Communication Research, Vol. 19, pp. 451-84.

Rowley, J. (1999), “Computer Mediated Communication - Is It Good for Organizations?”, Industrial and Commercial Training, Vol. 31 No. 2, pp. 72-4.

Schmitz, J. and Fulk, J. (1991), "Organizational Colleagues, Media Richness, and Electronic Mail”, Communication Research, Vol. 18, pp. 487-523.

Short, J., Williams, E. and Christie, B. (1976), The Social Psychology of Telecommunications, Wiley, New York.

Sillince, J., MacDonald, S., LeFang, B. and Frost, B. (1998), "E-Mail Adoption, Diffusion, Use and Impact Within Small Firms: A Survey of UK Companies", International Journal of Information Management, Vol. 18 No. 4, pp. 231-42.

Sproull, L. and Kiesler, S. (1986), "Reducing Social Context Cues: Electronic Mail in Organizational Communication”, Management Science, Vol. 32 No. 11, pp. 1492512.

Tobin, D.R. (1998), “Networking your Knowledge”, Management Review, Vol. 87, pp. 46-8.

Wareham, E. (1999), "Spam and e-mail abuses costing millions: Survey", Computing Canada, May, pp. 10-5.

Webster, J. and Trevino, L. (1995), "Rational and Social Theories as Complimentary Explanations of Communication Media Choices: Two Policy-Capturing Studies", Academy of Management Journal, Vol. 38, pp. 1544-72. 